\title{
Position Paper on the Diagnosis and Treatment of Peripheral Arterial Disease (PAD) in People with Diabetes Mellitus
}

\author{
Joint Statement of the German Diabetes Society (DDG), The German Angiology \\ Society (DGA) and The German Interventional Radiology Society (DeGIR)
}

\begin{abstract}
Authors (in alphabetical order)
Bernd Balletshofer ${ }^{1}$, Wulf Ito $^{2}$, Holger Lawall ${ }^{3}$, Nasser Malyar ${ }^{4}$, Yves Oberländer ${ }^{5}$, Peter Reimer6 ${ }^{6}$, Kilian Rittig7, Markus Zähringer ${ }^{8}$
\end{abstract}

\section{Affiliations}

1 Angiology Centre, Tübingen, Germany

2 Heart and Vascular Centre Oberallgäu, Kempten, Germany

3 Joint practice Prof. Dr. C. Diehm/Dr. H. Lawall, Max-Grundig Klinik Bühlerhöhe, Ettlingen, Germany

4 Clinic for Cardiology I - Coronary Heart Disease, Heart Failure and Angiology, University Hospital, Münster, Germany

5 Clinic for Internal Medicine 1 for Diabetology, Endocrinology, Cardiology and Angiology, Marienhospital, Stuttgart, Germany

6 Institute for Diagnostic and Interventional Radiology, Municipal Clinic, Karlsruhe, Germany

7 Clinic for Internal Medicine IV, Angiology and Diabetology, Klinikum Frankfurt (Oder), Germany

8 Clinic for Diagnostic and Interventional Radiology, Marienhospital, Stuttgart, Germany

\section{Bibliography}

DOI https://doi.org/10.1055/a-1018-9250

Exp Clin Endocrinol Diabetes 2019; 127 (Suppl 1): S105-S113

(c) J. A. Barth Verlag in Georg Thieme Verlag KG Stuttgart . New York

ISSN 0947-7349

\section{Correspondence}

Contact Person for the DDG

PD Dr. med. Kilian Rittig

Clinic for Internal Medicine IV, Angiology and Diabetology,

Klinikum Frankfurt (Oder)

Müllroser Chaussee 7

15236 Frankfurt (Oder)

Germany

kilian.rittig@klinikumffo.de

Contact Person for the DGA

Dr. med. Holger Lawall

Joint Practice Prof. Dr. C. Diehm/Dr. H. Lawall

Lindenweg 1

76275 Ettlingen

Germany

holger.lawall@gmail.com

Contact person for DeGIR

Prof Dr. med. Peter Reimer

Institute for Diagnostic and Interventional Radiology

Municipal Clinic Karlsruhe

Moltkestraße 90

76133 Karlsruhe

Germany

peter.reimer@partner.kit.edu
This position paper is based on the current German and international guideline recommendations [1-3] and serves as a short, clinically-oriented guideline for the diagnosis and treatment of patients with diabetes mellitus and peripheral arterial disease (PAD).

Peripheral circulatory disorders of the pelvic and leg arteries are one of the complications patients with diabetic mellitus suffer from. The term covers stenoses, occlusions and - to a lesser extent - aneurysmal vascular changes of the pelvic leg arteries.

Arterial vascular lesions mostly occur in later life, however, people with diabetes mellitus are often affected prematurely. In these patients, the time of the initial manifestation also depends on the duration of the disease and the quality of metabolic control. Only $25 \%$ of affected patients have symptoms.

Especially in patients with diabetes mellitus, atheroma of the peripheral vessels is aggravated by chronic inflammatory vessel wall processes and hypercoagulability.

Second to nicotine abuse, diabetes is the most important risk factor for the occurrence of PAD [4].

Patients with diabetes have a 2 to 4 -time higher risk of developing PAD than patients without diabetes.

Up to $30 \%$ of all patients with claudication and $50 \%$ of all patients with critical limb ischemia (CLI) are people with diabetes mellitus [5]. 
- Table 1 Classification of PAD according to Fontaine and Rutherford.

\begin{tabular}{|l|l|l|l|l|}
\hline \multicolumn{2}{|l|}{ Fontaine } & Rutherford & \multicolumn{2}{l|}{ Clinical picture } \\
\hline Stage & Clinical picture & Degree & Category & Asymptomatic \\
\hline I & Asymptomatic & 0 & 0 & Mild IC \\
\hline IIa & Walking distance $>200 \mathrm{~m}$ & $\mathrm{I}$ & 1 & Moderate IC \\
\hline IIb & Walking distance $<200 \mathrm{~m}$ & $\mathrm{I}$ & 2 & Severe IC \\
\hline & & $\mathrm{I}$ & 3 & Ischaemic pain at rest \\
\hline IV & Ischaemic pain at rest & II & 4 & Small patches necrosis \\
\cline { 2 - 5 } & Ulcer, gangrene & III & 5 & Large patches necrosis \\
\cline { 2 - 5 } & & III & 6 & \\
\hline
\end{tabular}

IC = Intermittent claudication.

PAD patients with diabetes have specific anatomical-morphological and clinical characteristics which must be considered in the diagnostic and therapeutic approach. Compared to people without diabetes mellitus, PAD in people with diabetes mellitus develops earlier, progresses more rapidly and more frequently changes over to critical limb ischemia (CLI). Anatomically-morphologically, a multi-segmental manifestation with long, calcified stenoses/occlusions of the lower leg arteries with insufficient collateral formation is typical. Clinically, people with diabetes mellitus often first consult their doctors because of a critical ischemia, in part because the intermittent claudication preceding a critical ischemia and the pain at rest can remain masked for a long time by the diabetic sensory polyneuropathy. The prognosis regarding a life without amputations is poor for people with diabetes mellitus. This is due, on the one hand, to the high ischemia and ulcer recurrence rates and the associated minor and major amputations, on the other hand it results from the high rate of comorbidities and co-prevalence of terminal organ damage such as cardiac and renal insufficiency, each of which on its own increases mortality.

The most significant consequences of diabetic peripheral circulatory disorders are foot lesions (ulcers and gangrene) and minor and major amputations as a result of ischemic or neuro-ischemic diabetic foot syndrome (DFS) ( $\triangleright$ Table 1 ).

\section{WHAT DOES IT MEAN?}

- The number of patients with PAD and diabetes is constantly increasing.

- The risk of amputation in people with diabetes mellitus is significantly increased in the presence of PAD.

- Timely detection of PAD reduces the amputation and cardiovascular event rates if treatment is in accordance with guidelines.

- Interdisciplinary cooperation and rapid revascularization are crucial in critical limb ischemia.

\section{Diagnostics of PAD in People with Diabetes Mellitus}

Non-invasive hemodynamic vascular function diagnostics in people with diabetes mellitus allows conclusions to be drawn about the severity of the circulatory disorder and provides prognostic information on the spontaneous course, cardiovascular risk and/or wound healing.

Targeted diagnostics facilitate choosing the appropriate therapy and enable monitoring of the course of the disease during and after vascular treatment.

In people with diabetes mellitus, these non-invasive diagnostic procedures should be used liberally if there is a suspicion of PAD, or if a foot lesion is present or is not healing.

\section{VASCULAR DIAGNOSTICS FOR PEOPLE WITH DIABETES MELLITUS}

- Clinical examination including recording of pulse status and capillary pulse as well as a qualitative comparison of skin colour and temperature

- Ultrasound ankle or toe pressure measurement (ABI; TBI)

- Colour-coded duplex sonography with pulse curve analysis

- Pulse oscillography of the digital arteries (DPO or LRR)

- Transcutaneous oxygen measurement (tcPO2)

In the clinical examination, it is important to examine the reactive skin circulation of the feet (capillary pulse) as well as perform palpation of the foot pulses. Although pulse examination of the lower extremities is helpful, the frequency of PAD is overestimated in the absence of pulses. Conversely, palpable foot pulses do not rule out the presence of PAD.

The capillary pulse as a reactive filling of the skin after pressure indicates the presence of a critical circulatory problem. 


\section{People with diabetes mellitus with PAD should have a regular clinical foot examination}

Ankle-brachial index (ABI) is determined using non-invasive doppler ultrasound to measure blood pressure at rest and/or after exertion and is a suitable test for detecting PAD.

Decreased peripheral pressure values are evidence of the presence of PAD and indicate the cardiovascular risk in the patient. The $A B I$ value with the lowest ankle artery pressure is decisive for the diagnosis of PAD. An ABI value at rest below 0.9 is deemed confirmation of the presence of PAD.

In the presence of media sclerosis $(A B \mid>1.3)$, the pulse curve analysis, pulse oscillography of the digital arteries and toe pressure measurement with determination of the TBI (toe-brachial index) are of particular importance and are used for the confirming PAD $[1,2]$.

\section{$A B I$ measurement important for confirming $P A D$ and risk stratification}

A vascular physician must be consulted if an $A B I<0.7$, systolic toe pressures $<40 \mathrm{mmHg}$, systolic ankle pressures $<70 \mathrm{mmHg}$ or a tcPO2 value $<30 \mathrm{mmHg}$ is determined in patients with diabetes [3]. In such cases, the risk of developing a foot ulcer is increased ( $\vee$ Table 2 ).

Regional foot ischemia may also be present with palpable foot pulses or almost normal toe pressure values (example: heel lesion in people with diabetes mellitus who require dialysis).

Non-invasive hemodynamic functional examinations of the leg vessels are required to assess severity, course and therapy stratification in patients with PAD.

Imaging procedures (ultrasound sonography, MR angiography, CT angiography, i.a. DSA) should be performed on symptomatic or at-risk patients only with therapeutic consequences.

Due to the co-morbidity of people with diabetes mellitus (kidneys, eyes, heart), interdisciplinary diagnostics and therapy planning are indicated.

\section{IMAGING DIAGNOSTICS}

- Colour-coded duplex sonography

- MR angiography of the pelvic leg arteries

- CT angiography of the pelvic leg arteries

- Intra-arterial angiography with $\mathrm{CA}$ or $\mathrm{CO}_{2}$

Colour-coded duplex sonography is of particular importance as a non-invasive method. It combines hemodynamic results with morphological findings and thus allows statements to be made on the localization and morphology of vascular lesions.

If there are unclarities, cross-sectional imaging using CE-MR angiography or CT angiography is recommended, however, it is important to take consideration of contraindications and side effects.

An intra-arterial angiography (non-selective angiography or selective high-resolution angiography) must be used to aid in deter-
- Table 2 Severity and prognosis of PAD based on Doppler values [1-3].

\begin{tabular}{|l|c|l|l|}
\hline & ABI & $\begin{array}{l}\text { Ankle } \\
\text { pressure } \\
(\mathbf{m m H g})\end{array}$ & $\begin{array}{l}\text { Toe pressure } \\
(\mathbf{m m H g})\end{array}$ \\
\hline PAD & $<0.9$ & & \\
\hline Media sclerosis & $>1.3$ & & $<30$ \\
\hline CLI & & $<50$ & $<40$ \\
\hline $\begin{array}{l}\text { Lack of wound heal- } \\
\text { ing }\end{array}$ & $<0.7$ & $<70$ & \\
\hline
\end{tabular}

mining whether a vascular segment can be grafted; the angiography can also be planned in intervention readiness, if necessary.

The often-limited kidney function in people with diabetes mellitus plays a special role in the administration of contrast agents, whereby contrast agent-induced nephropathy with the low or isoosmolar contrast agents commonly used today is significantly rarer. Hydration, co-morbidity and medication of the patients must be taken into account.

$\mathrm{CO}_{2}$ angiography can be specifically used in intervention procedures and offers a possibility for reducing contrast-induced renal dysfunction. In lower leg imaging, it is supplemented by the targeted administration of a few millilitres of a contrast agent containing iodine.

The indication for further radiological diagnostics should be made on an interdisciplinary level.

\section{Therapy of PAD in People with Diabetes Mellitus}

\section{Basic principles of therapy}

The therapy of PAD in people with diabetes mellitus has 2 basic goals: the improvement of peripheral blood flow in symptomatic patients as well as the therapy of vascular risk factors and concomitant diseases with special consideration of coronary and cerebrovascular vascular diseases ( $>$ Tables 3,4 ).

The basic treatment up to Fontaine stage Ilb includes structured walking training (e.g. also in sports groups for people with diabetes mellitus). Arm ergometric exercise treatments for walking contraindications or limitations (e.g. orthopaedic problems, PNP, DFS, etc.) are just as effective as walking training. In addition to vascular sports, weight reduction in cases of obesity, giving up nicotine in smokers and the treatment of arterial hypertension, hypercholesterolemia and diabetes mellitus are recognised therapeutic measures.

Conservative treatment in people with diabetes mellitus with symptomatic PAD includes the administration of platelet aggregation inhibitors (ASA $100 \mathrm{mg}$ or clopidogrel $75 \mathrm{mg}$ daily), the administration of statins and a structured vascular sports programme $[3,4]$.

\section{Anticoagulant therapy for PAD}

Patients with symptomatic arteriosclerosis require platelet aggregation inhibition with ASA or clopidogrel as a secondary prophy- 
- Table 3 Treatment goals.

\begin{tabular}{|c|c|c|}
\hline Goal & Stage & Therapy \\
\hline Inhibition of PAD progression & $\begin{array}{l}\text { Fontaine stage I-II } \\
\text { Rutherford } 1-3\end{array}$ & $\begin{array}{l}\text { - Therapy of risk factors } \\
\text { - Walking training }\end{array}$ \\
\hline Risk reduction of cardiovascular events & $\begin{array}{l}\text { Fontaine stage I-IV } \\
\text { Rutherford } 0-6\end{array}$ & $\begin{array}{l}\text { - Therapy of risk factors } \\
\text { - Walking training }\end{array}$ \\
\hline $\begin{array}{l}\text { Improvement of walking performance and } \\
\text { quality of life as well as pain reduction }\end{array}$ & $\begin{array}{l}\text { Fontaine II } \\
\text { Rutherford 2-4 }\end{array}$ & \\
\hline Risk reduction of peripheral vascular events & $\begin{array}{l}\text { Fontaine II-IV } \\
\text { Rutherford 3-6 }\end{array}$ & $\begin{array}{l}\text { - Reduction of further vascular interventions } \\
\text { - Avoidance of acute leg ischemia (ALI) }\end{array}$ \\
\hline Salvaging the leg & $\begin{array}{l}\text { Fontaine III-IV } \\
\text { Rutherford 4-6 }\end{array}$ & - Avoidance of minor or major amputation \\
\hline
\end{tabular}

- Table 4 Stage-adapted therapy methods. Source: [1].

\begin{tabular}{|c|c|c|c|c|}
\hline \multirow[b]{2}{*}{ Measure } & & \multicolumn{3}{|c|}{ Fontaine stage } \\
\hline & & III & III & IV \\
\hline $\begin{array}{l}\text { Risk factor management: } \\
\text { giving up nicotine, diabetes therapy, statins, blood pressure treatment }\end{array}$ & + & + & + & + \\
\hline $\begin{array}{l}\text { Platelet aggregation inhibitors: } \\
\text { ASA or clopidogrel }\end{array}$ & $(+)$ & + & + & + \\
\hline $\begin{array}{l}\text { Physical therapy: } \\
\text { structured vascular sports/sport for people with diabetes mellitus }\end{array}$ & + & + & & \\
\hline $\begin{array}{l}\text { Drug therapy: } \\
\text { cilostazol or naftidrofuryl }\end{array}$ & & + & & \\
\hline Structured wound treatment & & & & + \\
\hline Intervention therapy & & $+*$ & + & + \\
\hline Operative therapy & & $+*$ & + & + \\
\hline
\end{tabular}

laxis. Clopidogrel has demonstrated its superiority to ASA in symptomatic PAD patients [6]. ASA should not be routinely prescribed to patients with healthy cardiovascular systems [7-9], this is also valid for asymptomatic PAD patients [2]. Dual therapy with ASA and clopidogrel does not present any advantages over monotherapy with ASA [10], nor does therapy with ticagrelor compared to clopidogrel [11]. For patients with stable symptomatic PAD after invasive revascularization and a high risk of ischemic events, a combined therapy with rivaroxaban and ASA could show a reduction of the MACE (myocardial infarction, stroke, cardiovascular death) and MALE (major adverse limb event, severe circulatory disturbance/ amputation) endpoints [12]. This is equally valid for patients with diabetes mellitus.

\section{Therapy of hypertension in patients with PAD}

In general, all patients with arterial hypertension benefit from a reduction in blood pressure [13], and patients with PAD ( = high-risk patients) in particular have an improved cardiovascular prognosis. In patients with $\mathrm{PAD}, \mathrm{RR}<120 \mathrm{mmHg}$ and $>160 \mathrm{mmHg}$ result in more leg events [14]. For this reason, blood pressure should not be set too low in PAD patients. Renin-angiotensin system inhibitors are the drugs of choice for PAD patients. PAD patients with cardiac comorbidity can also be treated with beta-blockers for intermittent claudication and critical limb ischemia.

\section{RECOMMENDATION FOR ANTICOAGULANT THERAPY IN PAD}

Primary prevention

No indication for platelet aggregation inhibitors (PAI)

Secondary prevention

- Asymptomatic PAD: no clear indication for PAI

- Symptomatic PAD: clopidogrel $75 \mathrm{mg}$ better than ASA $100 \mathrm{mg}$

- High risk for ischemic events: rivaroxaban $2 \times 2.5 \mathrm{mg}+\mathrm{ASA}$ $100 \mathrm{mg}$ 


\section{RECOMMENDATION RR-TARGETS FOR PATIENTS WITH PAD}

RR target in PAD patients:

- $18-65$ years $<130 \mathrm{mmHg}$

- 65 years $<140 \mathrm{mmHg}$

- Overall $>120 \mathrm{mmHg}$

Renin-angiotensin system inhibitors are the drugs of choice

for PAD patients.

\section{CONCLUSION}

- In the case of confirmed PAD, a statin therapy with the maximum tolerable dosage for the patient (both with and without existing coronary heart disease) should be chosen to reduce the amputation and mortality risks.

- Target values for PAD: $L D L$ cholesterol $<70 \mathrm{mg} / \mathrm{dl}$ or lowering by more than $50 \%$ (with an initial LDL cholesterol level of $70-135 \mathrm{mg} / \mathrm{dl})$.

\section{Lipid therapy for diabetes and PAD}

\section{Statins and Ezetrol}

There is general consensus that cholesterol-lowering therapy has a positive effect on all-cause mortality and cardiovascular events in diabetic patients with PAD, but the outcome of studies on PADrelated endpoints is significantly weaker in diabetic patients. Existing recommendations result more from subgroup analyses of large endpoint studies and observational studies on coronary heart disease and cerebral angiopathy than from prospective randomized studies on PAD. Few studies suggest a reduction in the amputation rate [15] and an improvement in the pain-free walking distance. According to a current evaluation of the Veterans Affairs study, this applies both to the superior intensified therapy (e.g. atorvastatin $40-80 \mathrm{mg}$ ) and low-dose therapy (e.g. atorvastatin $10-20 \mathrm{mg}$ or simvastatin $10-40 \mathrm{mg}$ ) [16]. Although there are good indications for a reduction of the amputation and all-cause mortality rates, there are also smaller studies with no significant effect on the improvement of walking distance. On average, an improvement in the walking distance of approx. $160 \mathrm{~m}$ can generally be achieved in PAD patients [17].

The recommended target values for LDL cholesterol in PAD patients are an absolute $\mathrm{LDL}$ cholesterol target $<70 \mathrm{mg} / \mathrm{dl}$ or $1.8 \mathrm{mmol} / \mathrm{l}$ or a reduction of more than $50 \%$ for an initial LDL-C of $70-135 \mathrm{mg} / \mathrm{dl}$ or $1.8-3.5 \mathrm{mmol} / \mathrm{l}[2]$.

For Ezetrol, there are no robust statistics available on PAC.

\section{Fibrates}

Technically, fibrates lower triglycerides and increase HDL-C more than statins. Subgroup analyses (tertiary endpoint), e.g. of the FIELD study, show an absolute reduction of the microcirculationrelated amputation rate by a relative $36 \%$ in people with diabetes mellitus. The rate of major amputations and in patients with macroangiopathy was not different [18].

\section{PCSK9 inhibitors}

Subgroup analyses of the FOURIER study show a $42 \%$ reduction in PAD-related events (acute limb ischemia, amputation, or urgent peripheral revascularization) for patients with or without PAD at the beginning of the study [19]. This allows PCSK-9 inhibitors to be used in patients with progressive PAD on statin therapy or in patients with statin intolerance within the scope of the statutory health insurance funds' prescription ability and subject to the proviso of high therapy costs.

\section{Antidiabetics for PAD}

Biguanide

Metformin is also the oral antidiabetic of choice for people with diabetes and PAD. This is true even though the data is meagre in this respect. A recently published study again proves the positive effect on CV survival, but not on salvaging extremities and openness rate after peripheral revascularisation [20].

\section{Sulfonylureas and glinides}

For both substance groups, no robust statistics on PAD are available. They should generally only be used in justified exceptional cases when costs determine the therapy. Due to the relatively high risk of hypoglycaemia and the presumably unfavourable effects in patients with pre-existing coronary heart disease, these substance groups are of little relevance [21].

\section{Thiazolidinediones (PPAR-y agonists)}

For the only thiazolidinedione pioglitazone still available in Germany, positive endpoint studies for cardiovascular survival in patients with type 2 diabetes and prediabetic patients are available with the PROACTIVE and IRIS studies [22-26].

In the PROACTIVE study, amputations were also considered a primary endpoint. However, no significant advantage over the control group could be observed here. TZDs are contraindicated for existing heart failure.

\section{DPP4 inhibitors}

The cardiovascular endpoint studies SAVOR-Timi 53, EXAMINE, TECOS and CAROLINA show a non-inferiority of DPP-4 inhibitors to the investigated endpoints $C V$ death, non-fatal myocardial infarction or stroke compared to placebo or glimepiride. In the SAVORTimi-53 study, however, significantly more frequent hospitalization with saxagliptin due to heart failure was observed, which is why this substance should be used with caution in patients with known heart failure. Cardiovascular superiority or advantages in cases of simultaneous PAD have not been proven [27-31].

\section{GLP-1 agonists}

It was possible to demonstrate a positive effect on cardiovascular events such as fatal and non-fatal myocardial infarction and nonfatal stroke compared to placebos liraglutide, dulaglutide and semaglutide in endpoint studies [32-34]. However, semaglutide in combination with insulin shows an increased rate of microvas- 
cular eye complications, which is why this GLP-1 agonist should not be used in patients with uncontrolled diabetic retinopathy in combination with insulin for the time being [33]. With regard to PAD, however, no endpoint data are available for this substance group either.

\section{SGLT-2 inhibitors}

The EMPAREG-outcome study, the DECLARE-TIMI study and the CANVAS study provide data on the positive influence of the substances empagliflozin, dapagliflozin and canagliflozin on cardiovascular endpoints such as cardiovascular death, fatal and non-fatal myocardial infarction and stroke [35-38]. The EMPAREG outcome study and the DECLARE-TIMI study showed no increased amputation rate. For canagliflozin, which is not on the market in Germany, the amputation rate was significantly increased in the CANVAS study. In the recently published CREDENCE study, however, this was not observed [39]. The use of canagliflozin in patients with type 2 diabetes and PAD is not currently recommended.

\section{Basal insulin}

There are no endpoint studies available for basal insulin therapy for patients with PAD. No reduction of cardiovascular endpoints could be demonstrated for insulin degludec or, in the ORIGIN study, for insulin glargine. However, there was no increased incidence of cardiovascular complications meaning that the therapy can be considered safe for the cardiovascular system $[40,41]$.

Insulin should be used in people with type 2 diabetes mellitus especially in the presence of cardiovascular complications - except in the initial adjustment phase - as far as possible, only after optimized oral or GLP-1-based subcutaneous antidiabetic therapy.

\section{CONCLUSION}

- The data regarding antidiabetic therapy and PAD outcome is meagre.

- Metformin is also the oral antidiabetic of choice for people with diabetes and PAD.

- If PAD is confirmed, the next step should be to add an SGLT-2 inhibitor or a GLP-1 agonist.

- According to current data, the use of empagliflozin and dapagliflozin is safe. Canagliflozin, on the other hand, has shown an increased risk of amputation in a large outcome study (albeit in retrospective subgroup analysis).

- Therapy with basal insulin analogues is safe, but a reduction of cardiovascular events has not been proven.

\section{Principles of interventional therapy}

The interventional therapy of PAD depends on the stages of the disease and the affected vascular segments, which also applies for people with diabetes mellitus.

\section{Intermittent claudication}

In Fontaine stage IIb claudication, the therapy goal is an improvement of walking distance and quality of life. An initial intervention with subsequent structured walking training [42] has had the greatest success.

For aortoiliac disease, the primary openness rate 5 years after percutaneous intervention is - generally - stent implantation in over $90 \%$ [43]. For iliofemoral lesions with involvement of the femoral artery, a hybrid procedure should be considered. An intervention can also be considered even in femoropopliteal stenosis with lifestyle-limiting PAD, even if the restenosis rates are significantly higher. None of the guidelines recommend infrapopliteal, invasive therapy in the stage of intermittent claudication [44, 45].

Femoropopliteal surgery for short-stretch lesions with a length of less than $5 \mathrm{~cm}$ is still the indication for balloon dilatation only. Only from a lesion length of more than $10 \mathrm{~cm}$ do studies show a clear advantage of the additional implantation of self-expanding Nitinol stents [46]. Stents are also used in cases of recoil or dissection, even for shorter lesions. Paclitaxel-coated drug-eluting balloons (DEB) and stents (DES) showed a significant advantage over conventional PTA in multiple randomized controlled trials with postoperative monitoring periods of up to 5 years by reducing the restenosis rate $[47,48]$.

In December 2018, Katsanos published a meta-analysis using pooled data from 3 studies, including both DEB and DES, 2-5 years after implantation in which he determined a statistically significant higher all-cause mortality compared to patients treated with uncoated systems [49]. In January 2019, for the first time, the US Food and Drug Administration (FDA) published recommendations in which it recommended preventive health protection by carefully weighing the benefits and risks of the use of paclitaxel-coated balloons and stents. It was strongly recommended to inform affected patients before the intervention that the use of paclitaxel-coated devices can lead to an increased probability of death as of 2 years after implantation. This recommendation was endorsed by both the Federal Institute for Drugs and Medical Products/Bundesinstitut für Arzneimittel und Medizinprodukte (BfArM) and the affected German professional associations [50]. The most recent FDA publication on this subject appeared in August 2019 [51]. Our own analyses also confirm the increased mortality signal after 5 years with the use of paclitaxel-coated balloons and stents. At the same time, the missing data on possible mechanisms, the weakness of meta-analyses of very different studies with limited case numbers and the high effectiveness of paclitaxel-coated balloons and stents in preventing restenosis are also pointed out. However, the recommendations remain for the time being. In the meantime, these meta-analyses of three relatively small, differently designed randomised trials, which were not powered by mortality, are contradicted by analyses from large insurance data. A recently published analysis of US-American insurance data for a total of 83225 PTAtreated patients with PAD of which $29 \%$ of whom received medication-coated balloons, showed that patients treated with paclitaxel-coated balloons had significantly lower all-cause mortality, hospitalization and amputation rates after one year [59]. In a current health insurance data-based analysis from Germany with 
64771 patients (107112 procedures, 23137 of which with paclitaxel coating) and taking into account relevant, patient-related risk factors, no correlation was found between the use of paclitaxelcoated devices and increased mortality, neither for coated stents nor for coated balloons (Freisinger et al. Eur Heart J), both in the short term (30 days) and in the long term (up to 11 years). Even after repeated use of paclitaxel-coated devices in the course of the disease, there was no correlation between paclitaxel and mortality. Similar results have been obtained in further published studies $[60,61]$. In patients with recurrent restenosis, complex stenosis, critical limb ischemia or multiple concomitant diseases who are already at an increased mortality risk and for whom every reintervention increases this risk, the use of medication-coated balloons should be carefully considered.

\section{Critical limb ischemia}

If a circulatory disorder is present with acute danger to an extremity, initial revascularization should be sought in addition to treating the accompanying infection. Here the "Endovascular first" strategy has gained in importance and is also recommended in the current German S3 guideline [44]. In the treatment of the aortoiliac and femoropopliteal segments, there is no difference in the intervention strategy compared to intermittent claudication.

Various techniques are available for infrainguinal endovascular recanalization. In principle, angioplasty is to be preferred in intraluminal procedures. In designated centres, an infrapopliteal leg salvaging rate of over $90 \%$ can be achieved after percutaneous angioplasty [52].

Although a significant advantage of medicine-coated stents compared to balloon angioplasty could be demonstrated in small randomized controlled trials in terms of amputation-free survival after 5 years, the benefit of medicine-coated balloons cannot yet be conclusively evaluated $[53,54]$.

A further option is the possibility of gradual revascularisation [55]. Retrograde recanalization is successful in more than $80 \%$ of cases of critical limb ischemia without antegrade revascularization [56]. However, these complex procedures increase the duration of the intervention and the radiation exposure for the patient and the examiner. The previously prevailing opinion that the revascularisation results for diabetic feet are worse has been rendered obsolete. According to literature research, only the subgroup of people with diabetes mellitus requiring dialysis shows significantly poorer results both in the openness and the leg salvaging rate at each 50-70\% after 1 year, with a tendency towards a higher mortality rate [57]. In general, for people with diabetes mellitus and impaired kidney function and still functioning residual renal function, $\mathrm{CO}_{2}$ should be used as a negative intravascular contrast agent for angiography and interventional therapy for nephroprotection whenever possible [58].

\section{Acute limb ischaemia}

Interventional endovascular approaches are local catheterisation, mechanical thrombectomy by aspiration or special thrombectomy catheterisation. Modern concepts show 6 -month amputation rates of less than $10 \%$ with the best outcome at an occlusion duration of less than 14 days [43].

\section{Care after vascular interventions}

After peripheral vascular interventions, the administration of platelet aggregation inhibitors for secondary prophylaxis is absolutely necessary.

Statins are also indicated for secondary prophylaxis (independent of the LDL value). This not only improves clinical survival, but also significantly improves the bypass openness rate and walking ability.

The benefits of further drug treatments for people with diabetes mellitus are unclear.

Structured vascular training improves walking ability and clinical outcome even after revascularizing procedures.

\section{Conflict of Interest}

NM received lecture fees and travel assistance from: Bayer Vital, BARD, Medtronic. $\mathrm{HL}$ received lecture and consulting fees from Bayer Vital $\mathrm{GmbH}$, Pfizer, medac.

\section{German Diabetes Association: Clinical Practice Guidelines}

This is a translation of the DDG clinical practice guideline published in Diabetologie 2019; 14 (Suppl 2): S258-S266, DOI https://doi. org/10.1055/a-0858-4041.

\section{References}

[1] Lawall H, Huppert P, Rümenapf G. S3-Leitlinie zur Diagnostik, Therapie und Nachsorge der PAVK. AWMF-LL 065/003 2015.

[2] Aboyans V, Ricco JB, Bartelink MEL et al. 2017 ESC Guidelines on the diagnosis and treatmenrt of peripheral arterial disease, in collaboration with the European Society for Vascular Surgery (ESVS): Document covering arterosclerotic disease of extracranial carotid and vertebral, mesenteric, renal, upper and lower extremity arteriey. Eur Heart J 2018; 39: 763-816

[3] Hinchliffe RJ, Forsythe R, Apelquist ] et al. IWGDF Guideline on diagnosis, prognosis and management of peripheral arterial disease in patients with a foot ulcer and diabetes. Diabetes Metab Res Rev. 2019; in press

[4] Fowkes GFR, Rudan D, Rudan I et al. Comparison of global estimates of prevalence and risk factors for peripheral artery disease in 2000 and 2010: A systematic review and analysis. Lancet 2013, doi:10.1016/ S0140-6736 (13) 61249-0

[5] Malyar N, Freisinger E, Meyborg M et al. Amputations and mortality in in-hospital treated patients with peripheral arterial disease and diabetic foot syndrome. J Diab Compl 2016; 30: 1117-1122

[6] Cacoub PP, Bhatt DL, Steg PG et al. Patients with peripheral arterial disease in the CHARISMA trial. Eur Heart J 2009; 30: 192-201

[7] ASCEND Study Collaborative Group Effects of Aspirin for Pimary Prevention in Persons with Diabetes Mellitus. N Engl J Med 2018, doi:10.1056/NEJMoa1804988

[8] McNeil J], Wolfe R, Woods RL et al. Effect of aspirin on cardiovascular events and bleeding in the healthy elderly. N Eng J Med 2018, doi:10.1056/NEJMoa1805819 
[9] CAPRIE Steering Committee A randomised, blinded, trial of Clopidogrel versus aspirin in patients at risk of ischaemic events (CAPRIE). Lancet 1996; 348: 1329-1339

[10] Hiatt WR, Fowkes FG, Heizer G. EUCLID Trial Steering Committee and Investigatiors et al. Ticagrelor versus clopidogrel in symptomatic peripheral artery disease. N Engl J Med 2017; 376: 32-40

[11] Williams B, Mancia G, Spiering W et al. 2018 ESC/ESH Guidelines for the management of arterial hypertension. EUR Heart J 2018; 39: 3021-3104

[12] Soga $Y$, lida O, Takahara $M$ et al. Beta-Blocker treatment does not worsen critical limb ischemia in patients receiving endovascular therapy. J Arteroscler Thromb 2015; 22: 481-489

[13] Itoga NK, Taefik DS, Lee CK et al. Association of blood pressure measurements with peripheral artery disease events. Circulation 2018; 138 : 1805-1814

[14] Anand SS, Bosch J, Eikelboom JW et al. Rivaroxaban with or without aspirin in patients with stable peripheral or carotid artery disease: An international, randomised, double-blind, placebo-controlles trial. Lancet 2018; 391: 219-229

[15] Hsu CY, Chen YT, Su YW et al. Statin therapy reduces future risk of lower- limb amputation in patients with diabetes and peripheral artery disease. J Clin Endocrinol Metab 2017; 102: 2373-2381

[16] Arya S, Khakharia A, Binney ZO et al. Association of statin dose with amputation and survival in patients with peripheral artery disease. Circulation 2018; 137: 1435-1446

[17] Momsen $A H$, Jensen MB, Norager CB et al. Drug therapy for improving walking distance in intermittent claudication: A systematic review and meta-analysis of robust randomised controlled studies. Eur J Vasc Endo- vasc Surg 2009; 38: 463-474

[18] Rajamani K, Colman PG, Li LP et al. FIELD study investigators Effect of fenofibrate on amputation events in people with type 2 diabetes mellitus (FIELD study): A prespecified analysis of a randomised controlled trial. Lancet 2009; 373: 1780-1788

[19] Bonaca MP, Nault P, Giugliano RP et al. Low density lipoprotein cholesterol lowering with evolocumab and outcomes in patients with peripheral artery disease: Insights from the FOURIER Trial (further cardiovascular outcomes research with PCSK9 inhibition in subjects with elevated risk). Circulation 2018; 137: 338-350

[20] Khan SZ, Rivero M, Nader ND et al. Metformin is associated with improved survival and decreased cardiac events with no impact on patency and limb salvage after revascularization for peripheral arterial disease. Ann Vasc Surg 2019; 55: 63-77

[21] Bannister CA, Holden SE, Jenkins-Jones S et al. Can people with type 2 diabetes live longer than those without? A comparison of mortality in people initiated with metformin or sulphonylurea monotherapy and matched, non-diabetic controls? Diabetes Obes Metab 2014; 16: 1165-1173

[22] Dormandy JA, Charbonnel B, Eckland DJ et al. Secondary prevention of macrovascular events in patients with type 2 diabetes in the PROactive Study (PROspective pioglitAzone Clinical Trial In macroVascular Events): A randomised controlled trial. Lancet 2005; 366: 1279-1289

[23] Erdmann E, Dormandy JA, Massi-Benedetti M et al. The effect of piogli- tazone on recurrent myocardial infarction in 2445 patients with type 2 diabetes and previous myocardial infarction: Results from the PROactive (PROactive 05) Study. J Am Coll Cardiol 2007; 49: 1772-1780

[24] Wilcox R, Bousser MG, Betteridge D] et al. Effects of pioglitazone in patients with type 2 diabetes with or without previous stroke: Results from PROactive (PROspective pioglitAzone Clinical Trial In macro Vascular Events04). Stroke 2007; 38: 865-873

[25] Lincoff AM, Wolski K, Nicholls S] et al. Pioglitazone and risk of cardiovas- cular events in patients with type 2 diabetes mellitus: A metaanalysis of randomized trials. JAMA 2007; 298: 1180-1188
[26] Kernan WN, Viscoli CM, Furie KL et al. N Engl] Med 2016; 374 : 1321-1331

[27] Scirica BM, Braunwald E, Raz I et al. Heart failure, saxagliptin and dia- betes mellitus: Observations from the saVor - tiMi 53 randomized trial. Circulation 2015; 132: e198

[28] White WB, Cannon CP, Heller SR et al. alogliptin after acute coronary syndrome in patients with type 2 diabetes. N Engl J Med 2013; 369: 1327-1335

[29] Zannad F, Cannon CP, Cushman WC et al. Heart failure and mortality outcomes in patients with type 2 diabetes taking alogliptin versus placebo in EXaMinE: A multicentre, randomised, double-blind trial. Lancet 2015; 385: 2067-2076

[30] Green JB, Bethel MA, Armstrong PW et al. Effect of sitagliptin on cardio- vascular outcomes in type 2 diabetes. N Engl J Med 2015; 373: 232-242

[31] Rosenstock ]. CAROLINA®: Cardiovascular safety and renal microvascular outcome with linagliptin in patients with T2D at high vascular risk. Oral presentation at the 79th Scientific Sessions of the American Diabetes Association (ADA); 10 June 2019 San Francisco, CA, USA

[32] Marso SP, Daniels GH, Brown-Frandsen K et al. Liraglutide and cardiovascular outcomes in type2 diabetes. N Engl J Med 2016; 375: 311-322

[33] Marso SP, Bain SC, Consoli A. SUSTAIN-6 Investigators. et al. Semaglutide and cardiovascular outcomes in patients with type 2 diabetes. N Engl ] Med 2016; 375: 1834-1844

[34] Gerstein HC, Colhoun HM, Dagenais GR et al. Dulaglutide and cardio- vascular outcomes in type 2 diabetes (REWIND): A doubleblind, randomised placebo-controlled trial. Lancet 2019; 394: $121-130$

[35] Zinman B, Wanner C, Lachin JM et al. Empagliflozin, cardiovascular outcomes, and mortality in type 2 diabetes. N Engl J Med 2015; 373 : 2117-2128

[36] Wanner C, Inzucchi SE, Zinman B et al. Empagliflozin and progression of kidney disease in type 2 diabetes. N Engl J Med 2016; 375: 323-334

[37] Neal B, Perkovic V, Matthews DR. Canagliflozin and cardiovascular and renal events in type2 diabetes. N Engl J Med 2017; 377: 2099

[38] Wiviott SD, Raz I, Bonaca MP et al. Dapagliflozin and cardiovascular outcomes in type 2 diabetes. N Engl ] Med 2019; 380: 347-357

[39] Perkovic V, Jardine M], Neal B et al. CREDENCE Trial Investigators. Canagliflozin and Renal Outcomes in Type 2 Diabetes and Nephropathy. N Engl J Med 2019; 13 (24): 2295-2306. doi:10.1056/NEJMoa1811744 Epub 2019 Apr 14

[40] Holman RR, Coleman RL, Chan JCN et al. Effects of acarbose on cardio- vascular and diabetes outcomes in patients with coronary heart disease and impaired glucosetolerance (ACE): a randomised, double-blind, placebo-controlled trial. Lancet Diabetes Endocrinol 2017; 5: 877-886

[41] Gerstein HC, Bosch J, Dagenais GR. et al. Basal insulin and cardiovascular and other outcomes in dysglycemia. N Engl J Med 2012; 367: 319-328

[42] Greenhalgh RM, Belch J], Brown LC et al. The adjuvant benefit of angio- plasty in patients with mild to moderate intermittent claudication managed by supervised exercise, smoking cessation advice and best medical therapy: Results from two randomised trials for stenotic femoropopliteal and aortoiliac arterial disease. Eur J Vasc Endovasc Surg 2008; 36: 680-688

[43] Kersting J, Kamper L, Das M et al. Leitliniengerechte Therapie der pAVK - aktuelle Studienlage und Ausblick. Fortschr Röntgenstr 2019; 191: 311-322

[44] Lawall H, Huppert P, Zemmrich CS et al. S3-Leitlinie PAVK - Diagnostik, Therapie und Nachsorge der peripher arteriellen Verschlusskrankheit. VASA 2016; 45: (Suppl. 95) 1-100 
[45] Gerhard-Hermann MD, Gornik HL, Barrett C et al. 2016 AHA/ACC Guideline on the management of patients with lower extremity peripheral artery disease: Executive summary. Vasc Med 2017; 22: NP1-NP43

[46] Laird JR, Katzen BT, Scheinert D et al. Nitinol stent implantation vs. balloon angioplasty for lesions in the superficial femoral and proximal popliteal arteries for patients with claudication: Three-year follow-up from the RESILIENT randomized trial. J Endovasc Ther 2012; 19: 1-9

[47] Schlager O, Gschwandtner ME, Willfort-Ehringer A et al. Drug coated balloons in the superficial femoral artery. J Cardiovasc Surg 2018; 59: 60-69

[48] Dake MD, Ansel GM, Jaff MR et al. Durable clinical effectiveness with paclitaxel-eluting stents in the femoropopliteal artery: 5-year results of the Zilver-PTX randomized trial. Circulation 2016; 133: 1472-1483

[49] Katsanos K, Spiliopoulos S, Kitrou P et al. Risk of death following application of paclitaxel-coated balloons and stents in the femoropopliteal artery of the leg: A systematic review and meta-analysis of randomized controlled trials. J Am Heart Assoc 2018; 18: 1-13

[50] Empfehlung des BfArM Empfehlung für die Verwendung von Paclitaxel- beschichteten Stents (DES) und Ballons (DCB) in der Behandlung der peripheren arteriellen Verschlusskrankheit (pAVK). Referenz Nr. 00092/ 19. Stand 13.06.2019.

[51] https://www.fda.gov/medical-devices/letters-health-care-providers/ august-7-2019-update-treatment-peripheral-arterial-disease-paclitaxel- coated-balloons-and-paclitaxel

[52] Hinchliffe R], Andros G, Apelqvist J. A systematic review of the effectiveness of revascularization of the ulcerated foot in patients with diabetes and peripheral arterial disease. Diabetes Metab Res Rev 2012; 28: $179-217$
[53] Spreen MI, Martens JM, Knippenberg B et al. Long-term follow-up of the PADI trial: Percutaneous transluminal angioplasty versus drug-eluting stents for infrapopliteal lesions in critical limb ischemia. J Am Heart Assoc 2017; 14: 6

[54] Langhoff R, Behne A, Buschmann E. Promising role of drug-coated balloons in the tibial vessels? J Cardiovasc Surg 2018; 57: 667-676

[55] Manzi M. Innovations in the management of the diabetic foot. J Cardiovasc Surg 2018; 59: 653-654

[56] Walker CM. Tibiopedal access for crossing of infrainguinal artery occlu- sions: A prospective multicenter observational study. J Endovasc Ther 2016; 23: 839-846

[57] Bundesärztekammer, Kassenärztliche Bundesvereinigung (KBV) Arbeitsgemeinschaft der wissenschaftlichen medizinischen Fachgesellschaften (AWMF). S3-Leitlinie „Nierenerkrankungen bei Diabetes im Erwachsenenalter“. Nationale Versorgungsleitlinie. AWMF-LeitlinienRegister Nr. nvl/001d. 2015;

[58] Safian RD. $\mathrm{CO}_{2}$ angiography: Colorless, odorless but definitely not useless. Catheter Cardiovasc Interv 2017; 90: 449-450

[59] Long CA, Zepel L, Greiner MA et al. Use and 1-year outcomes with conventional and drug-coated balloon angioplasty in patients with lower extremity peripheral artery disease. Am Heart J 2019; 217 : 42-51

[60] Schneider PA, Laird JR, Doros G et al. Mortality not correlated with paclitaxel exposure: An independent patient-level meta-analysis of a drug-coated balloon. J Am Coll Cardiol 2019; 73 (20): 2550-2563

[61] Dake MD, Ansel GM, Bosiers M et al. Paclitaxel-coated zilver ptx drug- eluting stent treatment does not result in increased long-term all- cause mortality compared to uncoated devices. Cardiovasc Intervent Radiol 2019, doi:10.1007/s00270-019-02324-4 